\title{
Current principles in the management of obstructive sleep apnoea with mandibular advancement appliances
}

\author{
A. Johal,' and J. M. Battagel, ${ }^{2}$
}

\section{This paper looks at the role of mandibular advancement splints in the management of obstructive sleep apnoea, as part of a multidisciplinary approach. Clinical guidance is provided on the rationale for use, patient selection, design features and the associated risk to benefit ratio.}

$\mathrm{O}$ bstructive sleep apnoea (OSA) is a well-recognised breathing disorder, characterised by the repeated collapse of the upper airway during sleep and cessation of breathing. The prevalence in middle-aged males and females is reported to be $4 \%$ and $2 \%$ respectively. ${ }^{1}$ Subjects complain of excessive daytime sleepiness, headaches and impaired cognitive ability. Their partners frequently complain of the loud disruptive snoring with associated restlessness and involuntary leg movements during sleep. OSA subjects are at risk from severe medical complications, including hypertension, coronary heart disease and stroke, as a result of recurrent nocturnal hypoxaemia and hypercapnia. $^{2}$

The aetiology behind the narrowing of the pharyngeal airway is thought to arise from a combination of anatomical (retropositioned facial skeleton and reduced oropharyngeal dimensions) and patho-physiological factors (functional impairment of upper airway muscles).

The diagnosis of OSA is based on a comprehensive history from the patient and his/her sleeping partner (supported by the

${ }^{1}$ Senior Lecturer/Honorary Consultant ${ }^{2}$ Senior Lecturer, Dept of Orthodontics, St Bartholomew's and The Royal London School of Medicine and Dentistry, London E1 $1 B B$

${ }^{*}$ Correspondence to: $\mathrm{Mr}$ A. Johal, Department of Orthodontics, 3rd Floor, Dental Institute, New Road, Whitechapel, London E1 1BB

email:a.s.johal@mds.qmw.ac.uk

REFEREED PAPER

Received 05.05.00; Accepted 23.10.00

(C) British Dental Journal 2001; 190: 532-536
In brief

- The role of dentists, as part of a multidisciplinary team, in the management of obstructive sleep apnoea is being increasingly recognised.

- Mandibular advancement splints offer an alternative solution for selected patients with mild to moderate obstructive sleep apnoea.

- Further research is needed to evaluate the treatment effects of these appliances and to determine prognostic indicators for their success. use of questionnaires such as the Epworth Sleepiness Scale); ear, nose and throat examination (to identify any obvious physical obstructions); Body Mass Index (determined from the subject's weight and height) and overnight polysomnography (Fig. 1). The latter is regarded as the definitive investigation for the diagnosis of OSA, permitting the distinction between this and simple snoring. The severity of OSA is expressed as the Apnoea-Hypopnoea Index (AHI) and is the number of apnoeas (cessation of breathing lasting ten or more seconds) and hypopnoeas $50 \%$ reduction in tidal volume accompanied by a $4 \%$ or greater fall in oxygen saturation lasting 10 seconds or more) per hour of sleep. Lateral cephalometry has been shown to be of value as a diagnostic tool and for monitoring changes in the airway with mandibular advancement appliances. $^{3-5}$ More recently, the use of supine rather than traditional upright

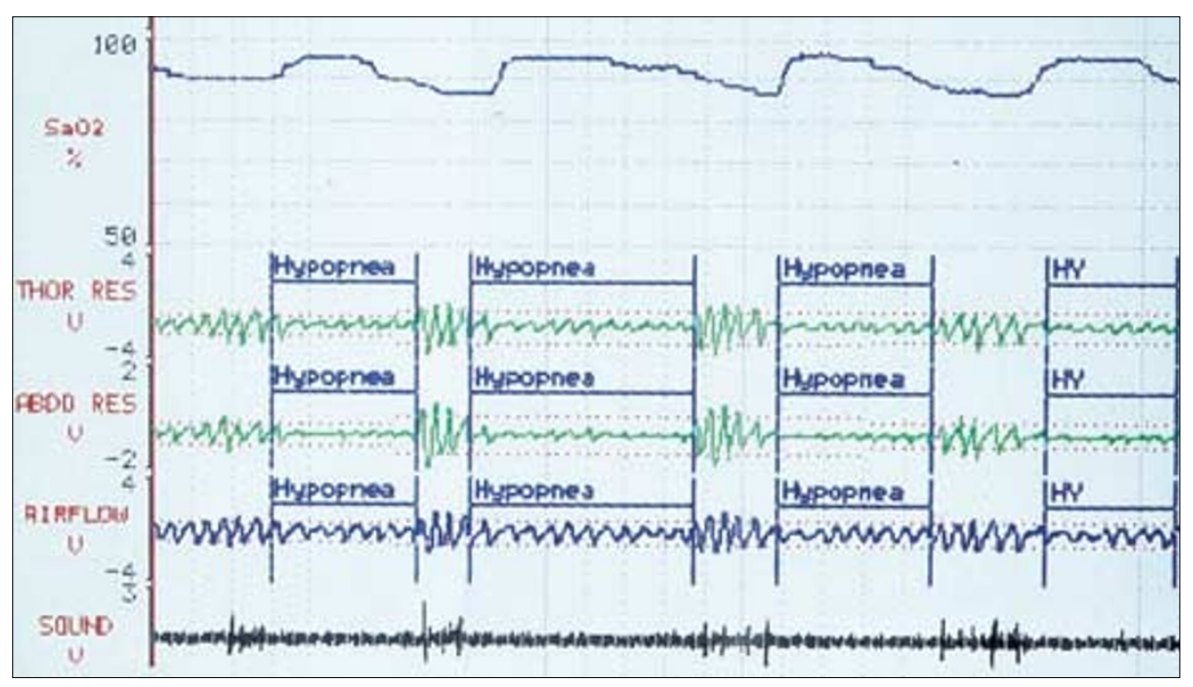

Fig. I Excerpt from a polysomnographic study showing three typical hypopnoeic events. The five traces illustrated are, from above downwards: blood oxygen saturation, thoracic and abdominal respiratory movement, airflow and sound. As the oxygen saturation level falls, during hypopnoea, an increase in thoracic and abdominal respiratory activity takes place with a sudden resurgence of airflow. At the same time a loud snore occurs. The oxygen saturation then returns to normal levels until the next episode occurs 


\section{PRACTICE sleeping disorders}

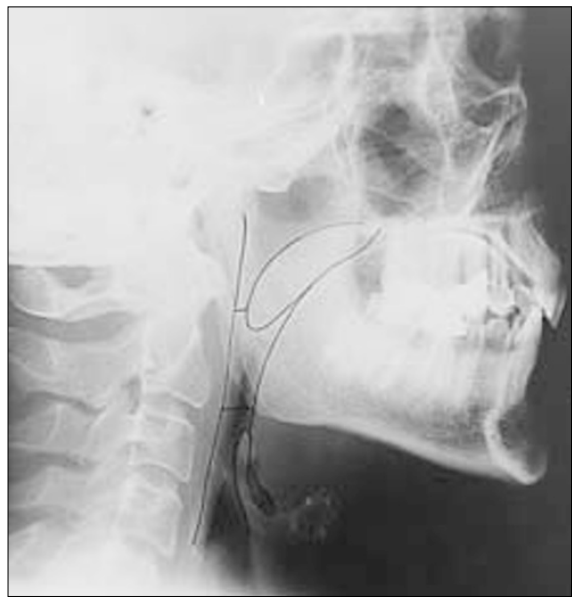

Fig. 2a Supine cephalometric radiograph taken with the patient in occlusion, illustrating the minimum post-palatal and post-lingual airways

radiographs has been reported to be of greater value, taking into account the influence of posture on upper airway dimensions (Fig. 2). ${ }^{6,7}$

Recognising the multifactorial nature of OSA, current management strategies focus on a multidisciplinary approach to care. The team includes a thoracic physician, ENT surgeon, orthodontist and maxillofacial surgeon. A number of diverse therapeutic approaches have been developed that attempt to intervene at various sites along the patho-physiological chain: these include both non-surgical and surgical therapies. For OSA, no currently available treatment provides the ideal combination of a high rate of success and patient compliance without complications. In conjunction with the elimination of aggravating factors, including weight loss and reduced alcohol intake, nasally-applied continuous positive airway pressure (CPAP) has become the major nonsurgical, long-term treatment of choice and is regarded as the 'gold standard'. ${ }^{8}$ This method maintains airway patency, during sleep by delivering a constant stream of filtered air under pressure through the nasal passages. As a consequence of poor longterm compliance with CPAP, estimated at between 60 and 70\%, ${ }^{9}$ the use of mandibular advancement splints (MAS) as an alternative treatment strategy has been increasingly recognised. ${ }^{4,5,7,10}$ It is however, important to stress that dental practitioners should only undertake the management of patients with OSA after their diagnosis has been confirmed by polysomnography and on the advise of an ENT surgeon or chest physician.

\section{Rationale for the use of mandibular advancement splints}

The role of dental appliances in the management of upper airway obstruction was

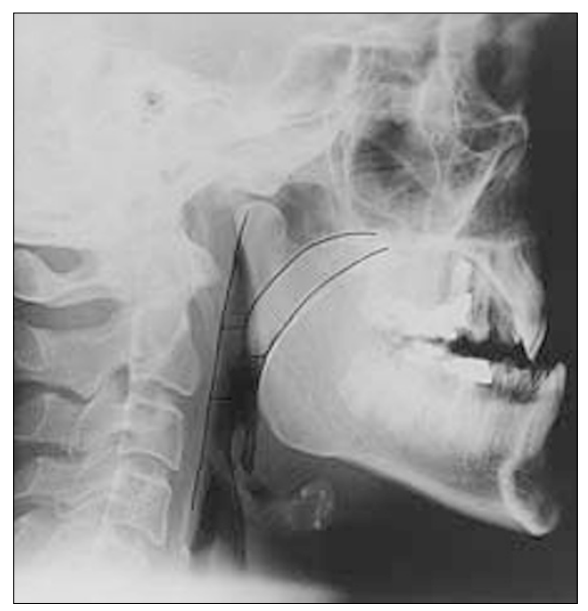

Fig. 2b Supine cephalometric radiograph taken with the mandible postured forward, illustrating an increase in both the postpalatal and post-lingual airway

recognised as early as $1902 .{ }^{11}$ The rationale for the use of MAS is that they may act to increase the size of the pharyngeal airway or otherwise reduce its collapsibility. A number of cephalometric studies, based on the use of a MAS, have shown an increase in upper airway dimensions in awake subjects (Fig. 3). ${ }^{3-7}$ The limitations of a 2-dimensional view, demonstrating antero-posterior changes, in evaluating airway responses to MAS must not be under estimated. However, only limited data are available on the effects of MAS in the transverse plane. Computerised tomography has been used to demonstrate that not only an increase in the airway space but also a change in shape accompanies the use of an oral appliance. ${ }^{12}$ More recently, Ryan et al., ${ }^{13}$ using videofluoroscopy, described increases in cross-sectional area of the upper airway, particularly in the velopharynx, when a MAS was worn.
Gale et al. ${ }^{14}$ described the use of low dose computerised tomography to visualise 3-dimensional changes in the airway following the insertion of an anterior mandibular positioning appliance (AMPA). The authors demonstrated an increase in minimum pharyngeal cross-sectional area accompanied the use of an AMPA but were improvement in symptoms, in light of the wide but unpredictable changes observed.

Despite the considerable variation in MAS design, the clinical effects appear remarkably consistent, OSA improves in the majority of subjects. Based on the findings of a review of twenty-one publications, undertaken by the American Sleep Disorders Association, the mean apnoeahypopnoea index (AHI) appeared to reduce from 47 to $19 .{ }^{13}$ However, whilst the authors completed a comprehensive review of all available published data on the use of intra-oral appliances for the management of OSA, the review has several limitations:

- It consisted entirely of case series, with relatively small sample sizes

- Randomised controlled studies were lacking

- Descriptions of the patients, their selection criteria and the study methods used were varied and incomplete.

More recently, a small number of well designed prospective randomised studies have been described in the literature. ${ }^{16-19}$ Two of these compared the use of a mandibular advancement splint with nasal $\mathrm{CPAP}^{16,17}$ and concluded that the MAS achieved substantial success $(45 \%$ reduction in AHI score), but were less effective unable to link this to patient response to

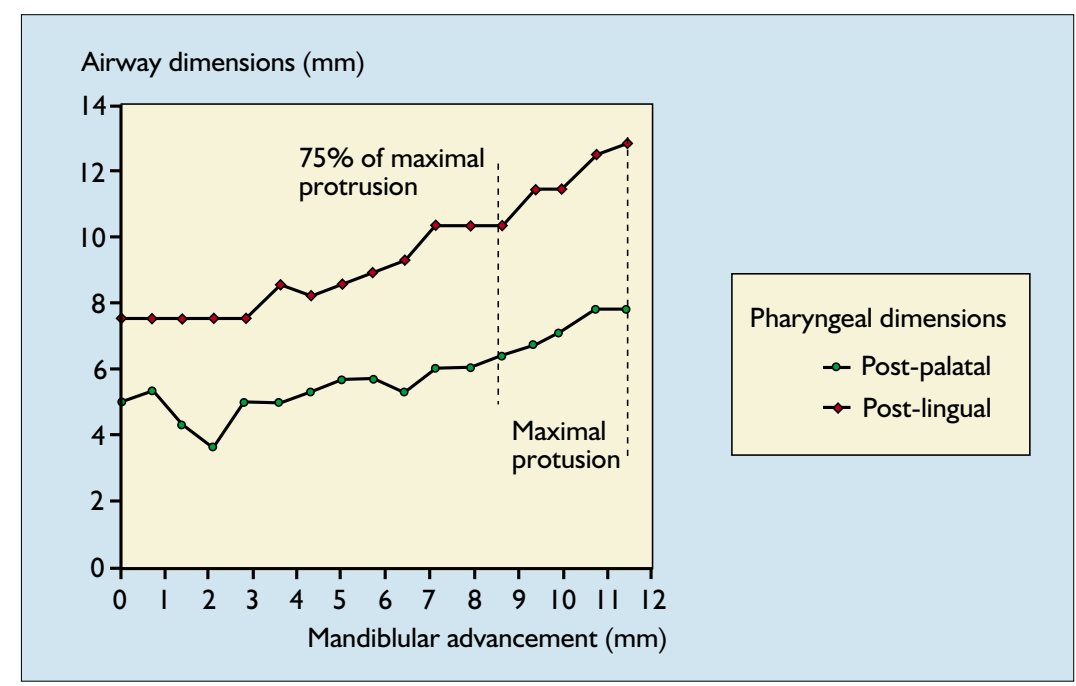

Fig. 3 A graphical representation of the change which takes place in both the post-palatal and post-lingual airway dimensions at different levels of mandibular advancement. It is particularly interesting to note the greater increase in the post-lingual airway associated with mandibular protrusion 

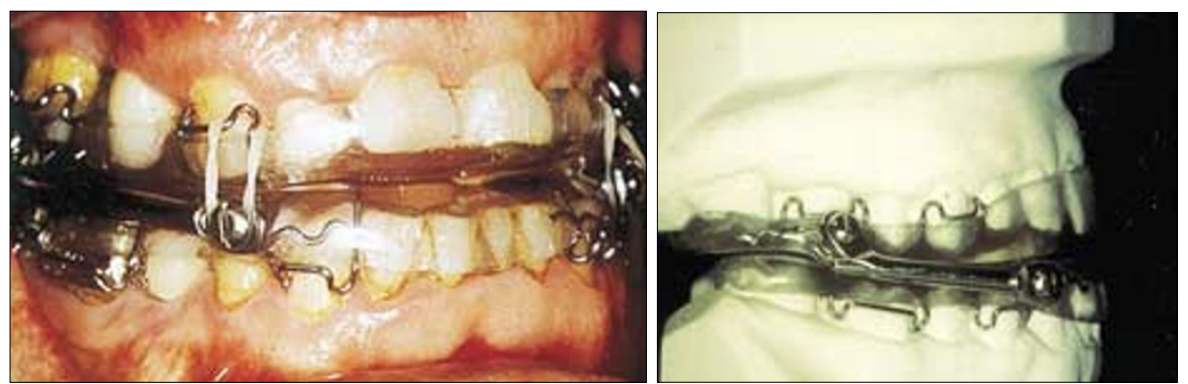

Figs 4a,b A removable Herbst mandibular advancement appliance. The connecting bar enables the mandible to be progressively advanced whilst the use of short intermaxillary elastics limits mouth opening during sleep

than $\mathrm{n}$-CPAP (70\% reduction in $\mathrm{AHI}$ score). Although the compliance rate was similar, the MAS was strongly preferred over n-CPAP. Bloch et al ${ }^{18}$ compared the effects of two different MAS designs with no treatment intervention and found the AHI reduced from 22.6 (no treatment intervention) to 8.7 (two-piece appliance) and 7.9 (single-piece appliance). Tegelberg et al. ${ }^{19}$ in a prospective randomised study compared the effects of surgery of the oropharynx with MAS therapy. The authors report that $95 \%$ of the patients who completed the study reduced their AHI by $50 \%$ or more. This compared favourably with the results of the surgical arm of their study. ${ }^{20}$

\section{Patient selection for mandibular advancement splints}

As yet there is no objective information to indicate which subjects will benefit from these devices. A number of cephalometric predictors have been described: where a favourable response to MAS may be expected. $^{21,22}$ These include:

- Reduced lower anterior facial proportions

- Orthognathic maxilla and mandible

- High position of hyoid

- Normal soft palate area and tongue proportion

- Relatively normal post-palatal and postlingual airway

Pringle and Croft developed the technique of sleep nasendoscopy to visualise the airway directly and thereby determine the site of obstruction in OSA patients during sleep. ${ }^{23}$ The rationale for developing such an investigation was that having determined the site of obstruction, the most appropriate type of treatment could be provided. Having performed over one hundred of these investigations the authors suggested a grading system, dividing patients into the following five categories:

\section{Simple palatal level snoring}

2. Single palatal level obstruction

3. Palatal level obstruction with intermittent orohypopharyngeal involvement

4. Sustained multi-segment involvement

5. Tongue-base level obstruction

Grade 1 is characterised by noisy snoring with no episodes of obstruction of the upper airway. In contrast, grades 2 to 5 demonstrate obstruction of the airway at differing anatomical sites.

Based on our team's clinical experience in applying this protocol to OSA subjects, it would appear that patients with grade 5 respond best to MAS therapy. Patients with grades 3 and 4 may also respond well, whilst those with gades 1 and 2 are not considered suitable for MAS therapy but ideal candidates for palatal surgery. A further refinement of the technique, in which the mandible is advanced, would permit an even more accurate assessment of who may benefit from MAS therapy. This relationship is presently being evaluated.

The Standards of Practice Committee of the American Sleep Disorders Association (ASDA) made the following recommendations with regard to the use of oral appliances for the treatment of obstructive sleep apnoea. ${ }^{24}$ Appliances are indicated for:

- Patients with mild OSA, who do not respond to or are not appropriate candidates for treatment with conservative measures such as weight loss or sleepposition change.
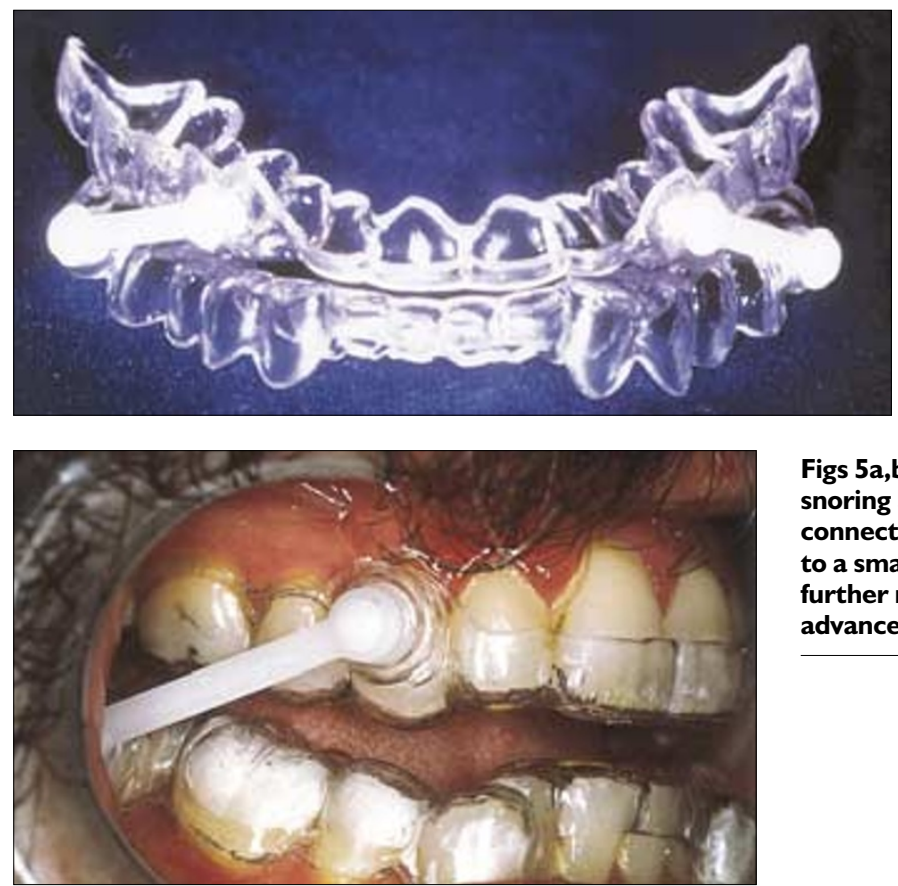

Figs 5a,b The Silensor Antisnoring appliance. The connecting bar can be changed to a smaller size, permitting further mandibular advancement 
- Patients with moderate to severe OSA who are intolerant of or refuse treatment with nasal CPAP.

\section{Design features of mandibular advancement splints}

Despite the wide variety of appliances described in the literature, most study groups have been small and there are few indications as to which design features may be important for success. The authors, based on their experience in the field, believe the following principles should be adhered to, for the reasons given below:

- A healthy dentition and supporting periodontium.

- Sufficient protrusion to maintain airway patency. Whilst the degree of forward protrusion attainable will vary from individual to individual, one should aim to achieve the maximum comfortable protrusion. This is often between 50 and 75\% of the subjects' maximum protrusion. In this respect, a MAS that allows incremental advancement offers clear advantages, for example, the removable Herbst (Fig. 4a,b) and Silensor appliances (Fig. 5a,b).

- Minimal vertical opening. A MAS which promotes mandibular opening results in a downward and backward rotation of the mandible with a concomitant posterior movement of both tongue and soft palate. This can negate the benefits to the airway from protrusion, resulting in the further narrowing of the pharyngeal airway, particularly at the level of the hypo-pharynx. This may explain why in a recent review of treatment outcomes with MAS therapy, as many as $40 \%$ of those treated were left with significantly higher AHIs. ${ }^{15}$

- Full occlusal coverage. This should prevent any unwanted changes in the occlusion resulting from over-eruption of unopposed teeth.

- Good retention. It is important to ensure the splint is well retained by the dentition, in order to prevent disengagement and thereby loss of the desired antero-posterior opening of the airway achieved through forward posturing of the mandible. The use of short intermaxillary elastics can help to prevent mouth open-

Fig. 6 A vacuum formed mandibular advancement appliance. In order to facilitate mouth breathing an anterior opening is incorporated between the upper and lower segments

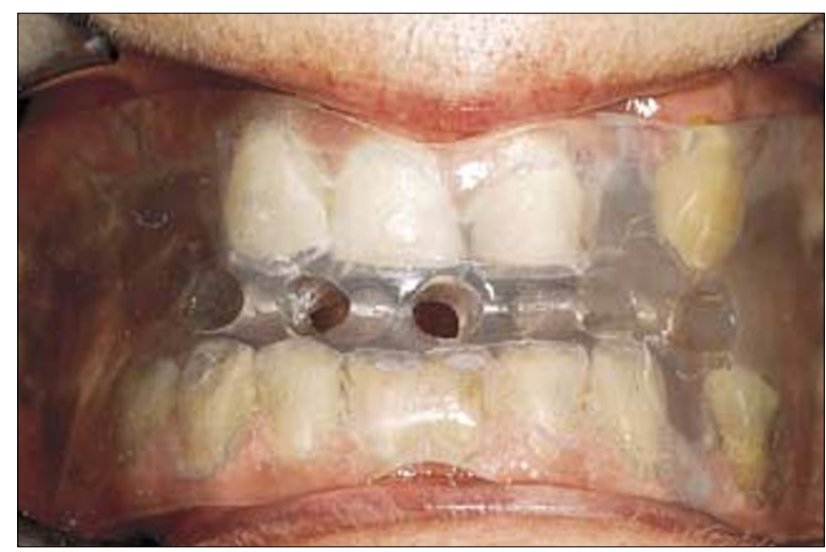

ing during sleep (Fig. 4a,b).

- Incorporation of an anterior opening in the splint. This is particularly helpful for those subjects who are mouth breathers and are provided with vacuum formed one-piece appliances (Fig. 6). In general, a two-piece device is preferred.

\section{Clinical management and follow-up}

As reported earlier, oral appliances may cause a worsening of OSA in certain individuals. It is therefore important that patients with moderate to severe OSA, treated with a MAS, should have regular follow-up visits to monitor compliance, assess the need for further appliance modification to ensure maximum clinical effectiveness and to evaluate the health of the dentition and supporting structures. These patients should also undergo an objective measurement of respiration during sleep, ideally polysomnography, with the MAS in-situ, to ensure a satisfactory therapeutic benefit.

\section{Advantages of mandibular advancement splint therapy}

- Clinically effective in mild to moderate OSA. Snoring, the most common cause for referral and disturbance for the rest of the family, has been significantly improved based on subjective and objective evaluations. ${ }^{15}$ As reported earlier, obstructive sleep apnoea improves in the majority of subjects, with $70 \%$ achieving a minimum of $50 \%$ reduction in AHI. Improvements in sleep quality and day-time sleepiness have also been reported. ${ }^{7,15}$

- Relatively inexpensive compared with the costs associated with other non-surgical and surgical treatment modalities.

- Readily accessible.

- Non-invasive and reversible in contrast to surgical treatment.

- Whilst data on long-term compliance are limited, overall compliance is reported to vary from 50 to $100 \%$. ${ }^{7,25,26}$

\section{Disadvantages of mandibular advancement splints}

- Short-term side effects. These include discomfort in the muscles of mastication, excessive salivation and an abnormal bite on awakening. These effects appear to be transient and without any lasting complication. $^{4,7}$

- Later complications may result in TMJ discomfort ${ }^{25}$ and changes in the occlusion. Bondermark and Lindman ${ }^{27}$ have demonstrated that following 2 years of treatment with MAS therapy no adverse effects on the cranio-mandibular status and function were observed. However, minor changes have been observed in the overjet, overbite, molar relationship and mandibular position, which require further evaluation. ${ }^{27,28}$ As such, these appliances should only be fitted by qualified personnel who are trained and experienced in oral health care, the temporomandibular joint and occlusion.

- The potential for OSA worsening, as a direct consequence of MAS therapy, has already been mentioned in relation to the design features. In a recent study by Gale et al., ${ }^{14}$ that MAS therapy may worsen the condition in a small number of subjects. 
Appropriate follow-up care is therefore essential and ASDA recommendations state: to ensure satisfactory therapeutic benefit, patients with moderate to severe OSA should undergo an objective measurement of respiration during sleep, with the oral appliance in place. ${ }^{24}$

\section{Conclusion}

Despite some of the present short-falls in the literature with regard to patient selection and long-term effects, a comparison of the risks and benefits of mandibular advancement splints with those of other available treatments, demonstrates that the MAS presents a useful alternative. This is particularly the case in patients who cannot tolerate nasally applied continuous positive airway pressure, the accepted 'gold standard' for treatment of OSA.

\section{Further information:}

BDA Information Centre, 64 Wimpole Street, London W1M 8AL

Tel: 02079350875

British Snoring and Sleep Apnoea Association, 1 Duncroft Close, Reigate, Surrey RH2 9DE

Tel: 01249701010

1 Young T M, Dempsey J, Skatrud J, Weber S, Badr S. The occurrence of sleep disordered breathing among middle-aged adults. New Eng J Med 1993; 328: 1230-1235.

2 Garcia-Rio F, Racionero A, Pino J et al. Sleep Apnea and hypertension. Chest 2000; 117:1417-1425.

3 Lowe A A, Santamaria J D, Fleetham J A, Price C. Facial morphology and obstructive sleep apnoea. Am J Orthod Dentofacial Orthop 1986; 90: 484-491.

4 Schmidt-Nowara W W, Mead T T, Hays M B. Treatment for snoring and obstructive sleep apnea. Chest 1991; 99: 1378-1385.

5 Eveloff S S, Rosenberg C L, Carlisle C C,
Millman R P. Efficacy of a Herbst mandibular advancement device in obstructive sleep apnea. Am J Respir Crit Care Med 1994; 149: 905-909.

6 Lowe A A. Dental appliances for the treatment of snoring and/or obstructive sleep apnea. In Kryger M, Roth T, Dement W. Principles and practice of sleep medicine. 2nd ed. pp722-735. Philadelphia: W B Saunders Co, 1994.

7 Johal A, Battagel J M. An investigation into the changes in airway dimension and the efficacy of mandibular advancement appliances in subjects with obstructive sleep apnoea. $\mathrm{Br} \mathrm{J}$ Orthodont 1999; 26: 205-210.

8 Sullivan C E, Issa F G, Berthon-Jones M, Eves L. Reversal of obstructive sleep apnoea by continuous positive airway pressure applied through the nares. Lancet 1981; 1: 862-865.

9 Engleman H M, Martin S E, Douglas N J. Compliance with CPAP therapy in patients with sleep apnea/hypopnea syndrome. Thorax 1994; 49: 263-266.

10 L'Estrange P R, Battagel J M, Harkness B, Spratley M H, Nolan P J, Jorgenson G I. A method of studying adaptive changes of the oropharynx to variation in mandibular posture in patients with obstructive sleep apnoea. J Oral Rehab 1996; 23: 699-711.

11 Robin P. Glossoptosis due to atresia and hypotrophy of the mandible. Am J Dis Child 1934; 48: 541-547.

12 Lowe A A, Fleetham J, Ryan F, Mathews B. Effects of a mandibular repositioning appliance used in the treatment of obstructive sleep apnea on tongue muscle activity. In Issa F G, Surratt P M, Remmers J E. Sleep and respiration. 1st ed. pp 395-405. New York: Wiley-Liss, 1990

13 Ryan C F, Love L L, Fleetham J A, Lowe A A. Mandibular advancement oral appliance therapy for obstructive sleep apnoea: effect on awake calibre of the velopharynx. Thorax 1999; 54: 972-977.

14 Gale D J, Sawyer R H, Woodcock A, Stone P, Thompson R, O’Brien K. Do oral appliances enlarge the airway in patients with obstructive sleep apnoea? A prospective computerized tomographic study. Eur J Orthodont 2000; 22: 159-168.

15 Schmidt-Nowara W, Lowe A A, Wiegand L, Cartwright R, Perez-Guerra F, Menn S. Oral apliances for the treatment of snoring and obstructive sleep apnea. Sleep 1995; 18: 501-510.

16 Ferguson K A, Ono T, Lowe A, Keenan M D, Fleetham J A. A randomized crossover study of an oral appliance vs nasal-continuous positive airway pressure in the treatment of mildmoderate obstructive sleep apnoea. Chest 1996; 109: 1269-1275.

17 Clark G T, Blumenfeld I, Yoffe N, Peled E, Lavie $\mathrm{P}$. Crossover study comparing the efficacy of continuous positive airway pressure with anterior mandibular positioning devices on patients with obstructive sleep apnoea. Chest 1996; 109: 1477- 1483.

18 Bloch K E, Iseli A, Zhang J N et al. A randomized, controlled crossover trial of two oral appliances for sleep apnoea treatment. Am J Respir Crit Care Med 2000; 162: 246-251.

19 Tegelberg A, Wilhelmsson B, Walker-engstrom et al. Effects and adverse events of a dental appliance for the treatment of obstructive sleep apnoea. Swed Dent 1999; 23: 117-126.

20 Wilhelmsson B, Tegelberg A, Walker-Engstrom et al. A prospective study of a dental appliance compared with uvulopalatopharyngoplasty in the treatment of obstructive sleep apnoea. Acta Otolaryngol 1999; 119: 503-509.

21 Mayer G, Meier-Ewert K. Cephalometric predictors for orthopaedic mandibular advancement in obstructive sleep apnoea. Eur J Orthodont 1995; 17: 35-43.

22 Battagel J M. Obstructive sleep apnoea: Fact not Fiction. Br J Orthodont 1996; 23: 315-324.

23 Pringle M B, Croft C B. A grading system for patents with obstructive sleep apnoea based on sleep nasendoscopy. Clin Otolaryngol 1993; 18: 480-484.

24 American Sleep Disorders Association Report. Practice parameters for the treatment of snoring and obstructive sleep apnea with oral appliances. Sleep 1995; 18: 511-513.

25 Clark G T, Arand D, Chung E, Tong D. Effect of anterior mandibular positioning on obstructive sleep apnea. Am Rev Respir Dis 1993; 147: 624-629.

26 Ichioka M, Tojo N, Yoshizawa M et al. A device for the treatment of obstructive sleep apnea: a preliminary study. Otolaryngol Head Neck Surg 1991; 104: 555-558.

27 Bondermark L, Lindman R. Craniomandibular status and function in patients with habitual snoring and obstructive sleep apnoea after nocturnal treatment with a mandibular advancement splint: a 2-year follow-up. Eur J Orthodont 2000; 22: 53-60.

28 Bondermark L. Does 2 years' nocturnal treatment with a mandibular advancement splint in adult patients with snoring and OSAS cause a change in the posture of the mandible? Am J Orthod Dentofacial Orthop 1999; 116: 621-628. 